Check for updates

Berkshire

davidoliver372@googlemail.com Follow David on Twitter @mancunianmedic Cite this as: $B M / 2021 ; 372: n 832$ http://dx.doi.org/10.1136/bmj.n832 Published: 31 March 2021

\title{
ACUTE PERSPECTIVE
}

\section{David Oliver: When visitors return to the wards}

\section{David Oliver consultant in geriatrics and acute general medicine}

During the peaks of the covid-19 pandemic serious restrictions were imposed on ward visits from patients' carers, family, and friends, for infection control purposes. Limited exceptions were made for seriously ill or dying, deteriorating patients. But far fewer beds are now designated for covid patients, and wards specified as "red" or "hot" areas have reverted to accommodating patients without the virus.

Soon, ward visiting rules around the country will relax. But a year without ward visitors has given me pause to reflect on how different things were for staff, patients, and their families. I now wonder whether we should return to completely unrestricted visiting-so common before the pandemic, championed by advocacy groups such as John's Campaign, ${ }^{1}$ and enthusiastically endorsed by me and other clinicians. One of the biggest stressors for staff on covid wards was the number of upsetting phone calls they had to make to patients' relatives, who had not been able to come in to see them at all since admission and who might have put themselves or their family at risk if they had.

If professionals were distressed, then the fear, concern, and frustration for relatives were surely worse. The calls about deterioration and dying were especially harrowing. Let's face it-the phone is not the most sensitive medium for conversations where touch, facial expression, and body language matter. And, although video calls did sometimes allow families to see their loved ones on screen, many patients were so sick or cognitively impaired, or had visual or hearing loss, that such calls were hard and no substitute for a relative at the bedside.

It's harder to explain or gain acceptance for news-good or bad-or to establish trust in care when relatives haven't met clinical staff and developed a rapport with them. It's also harder if they haven't seen for themselves how their relative is, the care being given, or how busy the staff are with other patients. Many of those phone calls wouldn't have been necessary if we'd been able to speak to visitors face to face during our working day.

Visitors often have deep personal knowledge of patients' lives outside hospital, as well as their medical conditions and history, and they often have crucial roles as unpaid carers. They can be brilliant allies and partners in care and are often the first to spot when patients aren't quite right. They can also keep us on our toes by spotting problems or asking questions we hadn't considered, and our conversations with them can help patients when they return home. They can assist with care at mealtimes in a way that few professionals could. So, wouldn't we welcome the return of unrestricted visiting with open arms?

After a year of visitor-free pandemic medicine, I'm no longer sure that it's that simple. Even with personal protective equipment and infection control measures it's been far more possible to see many patients on a ward round without it over-running. We've been able to focus more fully on clinical decisions and patient review, which can be very hard when being interrupted repeatedly (often by relatives of patients we're not seeing). Interruptions and distractions can worsen patient safety.

Similarly, we're presently not trying to work in public spaces while being stared at and observed-often by people clearly pleading for us to drop what we're doing and see them or their relative next, which can all add to stress in an already fraught atmosphere with a tired workforce. We don't have to worry constantly about sensitive conversations being overheard and patient confidentiality being breached. With multi-patient bays, visitors for other patients can also compromise their privacy and dignity and rest.

Some patients' relationships with their carers or family members can be part of the problems that led to admission or can make leaving hospital a worry: we need a safe space to discuss that too. And sometimes, although we're well aware that a patient is confused, frail, or fearful, we need a chance to talk to them about what they want and what they understand, while treating them as an

individual-which can be hard when someone at the bedside wants to be involved too. We have only a few minutes with each patient, and sometimes those few minutes end up being spent almost entirely on a visitor.

So yes, we want to see visitors back. But perhaps the pandemic has taught us that, at least during the day's main ward round, limits need to be imposed on visits and some expectations reinforced about interruptions, appropriate times to speak to clinical teams, and realistic expectations. Consideration is a two way street.

Competing interests: See bmj.com/about-bmj/freelance-contributors.

Provenance and peer review: Commissioned; not externally peer reviewed.

John's Campaign. https://johnscampaign.org.uk/. 